\title{
Value-at-Risk and Expected Stock Returns: Evidence from Pakistan
}

\section{Javed Iqbal* and Sara Azher**}

\begin{abstract}
This study investigates whether exposure to downside risk, as measured by value-at-risk (VaR), explains expected returns in an emerging market, i.e., Pakistan. We find that portfolios with a higher VaR are associated with higher average returns. In order to explore the empirical performance of $V a R$ at the portfolio level, we use a time series approach based on 25 size and book-to-market portfolios. Based on monthly portfolio data for October 1992 to June 2008, the results show that VaR has greater explanatory power than the market, size, and book-to-market factors.
\end{abstract}

Keywords: Value-at-risk, emerging market, Fama-French factors.

JEL classification: C32, G32.

\section{Introduction}

The most important implications of the capital asset pricing model (CAPM) (see Sharpe, 1964; Lintner, 1969; Black, Jensen, \& Scholes, 1972) are that (i) the expected return on a risky asset is linearly and positively related to its systematic risk, and (ii) only the asset's beta captures crosssectional variations in expected stock returns; other variables have no explanatory power. However, the empirical evidence of the last few decades suggests that many alternative risk and nonrisk variables are able to explain average stock returns. These include size (Banz, 1981), the ratio of book equity to market equity (Fama \& French, 1992, 1993, 1995, 1996; Stattman, 1980; Rosenberg, Reid, \& Lanstein, 1985; Chan, Hamao, \& Lakonishok, 1991), the price/earnings ratio (Basu, 1977), leverage (Bhandari, 1988), liquidity (Pastor \& Stambaugh, 2003), and value-at-risk (VaR) (Bali \& Cakici, 2004; Chen, Chen, \& Chen, 2010).

Bali and Cakici (2004) investigate the relationship between portfolios sorted by $\mathrm{VaR}^{1}$ and expected stock returns and find that $\mathrm{VaR}$,

\footnotetext{
*Assistant Professor, Institute of Business Administration, Karachi, Pakistan.

*** Department of Statistics, University of Karachi, Pakistan.

${ }^{1}$ The k-day $\mathrm{VaR}$ on day $t$ with probability $1-\alpha$ is defined as prob. $\left[p_{t-k}-p_{t} \leq \operatorname{VaR}(t, k, \alpha)\right]=1-$ $\alpha$ where $p_{t}$ is the day $t$ price of the asset. VaR is based on both the mean and variance of returns, so it is not exactly a measure of risk but rather a measure of value-at-risk.
} 
size, and liquidity explain the cross-sectional variation in expected returns, while beta and total volatility have almost no explanatory power at the stock level. Furthermore, the strong positive relationship between average returns and $\mathrm{VaR}$ is robust for different investment horizons and loss-probability levels.

$\mathrm{VaR}$ is a popular measure of risk value among finance practitioners and regulators of banks and financial institutions because it provides a single number with which to quantify the monetary loss associated with a portfolio exposed to market risk with a certain probability. If portfolios sorted by $\mathrm{VaR}$ result in higher returns associated with a higher $\mathrm{VaR}$, then this can prove to be extremely valuable information for investors, portfolio managers, and financial analysts who can construct and recommend profitable portfolio strategies accordingly. The Basel II accord on banking supervision also recommends using $\mathrm{VaR}$ to measure the market risk exposure of banking assets. It is, therefore, an equally useful measure for market regulators and policymakers, making it important to investigate the asset pricing implications of $\mathrm{VaR}$ as a risk factor.

Apart from Bali and Cakici's (2004) pioneering study on the US and a recent study on Taiwan by Chen et al. (2010), there are no empirical studies on this aspect of asset pricing in the context of emerging and developed markets. The major objective of our study is to test whether the maximum likely loss as measured by $\mathrm{VaR}$ can explain the cross-sectional and time variations in average returns in Pakistan as an emerging market.

We have selected Pakistan for this analysis because it typifies an emerging market, exhibiting features such as higher returns associated with higher volatility, lower liquidity, a relatively high market concentration, and infrequent trading of many stocks. ${ }^{2}$ Additionally, given that determining the validity of an economic or financial theory or model requires testing it under different conditions, this study aims to contribute to the literature by testing the relationship between $\mathrm{VaR}$ and expected returns accordingly. Our analysis reveals that constructing VaR as the common risk factor enables a better explanation for time variations in average portfolio returns sorted by size and book-to-market factors as compared to the Fama-French common factors.

\footnotetext{
${ }^{2}$ Khawaja and Mian (2005) elaborate further on some features of the market; Iqbal (2012) provides an overview of the stock market in Pakistan.
} 


\section{Literature Review}

Over the last six decades, downside risk has been studied from the perspective of explaining asset returns. The concept of measuring downside risk dates back to Markowitz (1952) and Roy (1952). Markowitz (1952) provides a quantitative framework for measuring portfolio risk and return. The study utilizes mean returns, variances, and covariances to develop an efficient frontier on which every portfolio maximizes the expected return for a given variance or minimizes the variance for a given expected return.

Roy (1952) explains the same equation as Markowitz, connecting the portfolio variance of returns to the variance of returns of the constituent securities. As Markowitz (1959) points out, investors are interested in minimizing the downside risk because this would help them make better decisions when faced with nonnormal security return distributions. Consequently, he suggests assessing downside risk using (i) a semivariance computed from the mean return or below-mean semivariance $\left(\mathrm{SV}_{\mathrm{m}}\right)$ and (ii) a semivariance computed from a target return or below-target semivariance $\left(\mathrm{SV}_{\mathrm{t}}\right)$. The two measures compute a variance using only the returns below the mean return $\left(\mathrm{SV}_{\mathrm{m}}\right)$ or target return $\left(\mathrm{SV}_{\mathrm{t}}\right)$. In addition, the study compares several risk measures, including standard deviation, expected value of loss, expected absolute deviation, probability of loss, and maximum loss.

Quirk and Saposnik's (1962) study establishes the theoretical dominance of the semivariance over the variance. Mao (1970) argues in favor of using the semivariance given that investors will be interested specifically in the downside risk. Bawa (1975) and Fishburn (1977) identify the lower partial moment as a general family of below-target risk measures (one of which is the $\mathrm{SV}_{\mathrm{t}}$ ) that describe below-target risk in terms of risk tolerance. Bawa and Lindenberg (1977), whose study develops a mean lower partial moment (MLPM) model based on downside risk, present the CAPM as a special case of the MLPM, pointing out that the latter must explain the data at least as well as the CAPM. Harlow and Rao (1989) provide empirical support for the Bawa-Lindenberg downside risk model.

Nawrocki's (1999) study of downside risk differentiates between the two types of semivariance risk measures presented by Markowitz (1959). Eftekhari and Satchell (1996) and Claessens, Dasgupta, and Glen (1995) observe nonnormality in emerging markets. Bekaert, Erb, Harvey, and Viskanta (1998) note that skewness and kurtosis are significant risk factors for emerging market equities. Harvey and Siddique (2000) and Bekaert and Harvey (2002), respectively, argue that skewness is a significant risk factor in both developed and emerging markets. 
Estrada $(2000,2002)$ investigates different risk measures and finds that semi-standard deviation is the relevant measure of risk for emerging markets. Dittmar (2002) determines the influence of a security's skewness and kurtosis on investors' expected returns. Bali and Cakici (2004), Bali, Gokcan, and Liang (2007), and Bali, Demirtas, and Levy (2009) consider $\mathrm{VaR}$ an alternative risk factor that helps explain the cross-section of stock returns. Chung, Johnson, and Schill (2006) argue that a set of co-moments taken together may be more reliable than individual co-moments. Ang, Chen, and Xing (2006) demonstrate how the downside beta term helps explain cross-sectional variations in average stock returns.

Iqbal, Brooks, and Galagedera (2010) evaluate the CAPM and MLPM for an emerging market over the period September 1992 to April 2006. Their empirical results support both models when performed against an unspecified alternative, but support the CAPM when an MLPM alternative is specified. Blitz, Pang, and van Vliet (2013) study the significant effects of volatility in emerging markets. De Groot, Pang, and Swinkels (2012) demonstrate the significant presence of value, momentum, and size effects in frontier emerging markets over the period 1997 to 2008; the authors argue that transaction costs or risk do not adequately explain these three market factors.

The disadvantage of the MLPM, which measures the relationship between asset returns and downside movement in the market, is that it yields a regression-based estimate, which may not be easily understood by common investors. The VaR, on the other hand, is a monetary value that readily captures downside risk. Accordingly, this study focuses on providing empirical evidence on the efficacy of $\mathrm{VaR}$ as a risk measure for Pakistan's emerging market. In addition to providing time series evidence, we carry out a cross-sectional regression analysis of VaR and average portfolio returns sorted with respect to VaR. This differentiates the study from Bali and Cakici (2004), for example, who do not provide estimates for the cross-sectional relationship between $\mathrm{VaR}$ and expected returns.

\section{Data, Sample Selection, and Variables}

Our primary source of data is the Karachi Stock Exchange (KSE) the largest of Pakistan's three stock exchanges. Conducting asset-pricing tests based on daily data is problematic, given that daily returns tend to be nonnormal and that stocks are traded infrequently in this market. We have, therefore, used monthly data on continuously compounded stock returns for 231 stocks traded on the KSE from October 1992 to June 2008 (see Appendix 1). 
The number of firms in the sample varies over the sample period. Figure 1 shows the number of firms at the end of December for each year of the sample period. We have 149 firms in the first year and 231 stocks at the end of June 2008, which provides us with a reasonable volume of data for analysis. The sample includes both financial and nonfinancial firms across all sectors of the KSE. As with other studies that use price databases, firm survival may be an issue, implying that the data overstates the importance of certain factors in such cases. In order to minimize this likelihood, we have applied a smaller level of significance- 1 percent instead of 5 and 10 percent-in the statistical tests conducted.

Figure 1: Number of firms included in the sample over the sample period

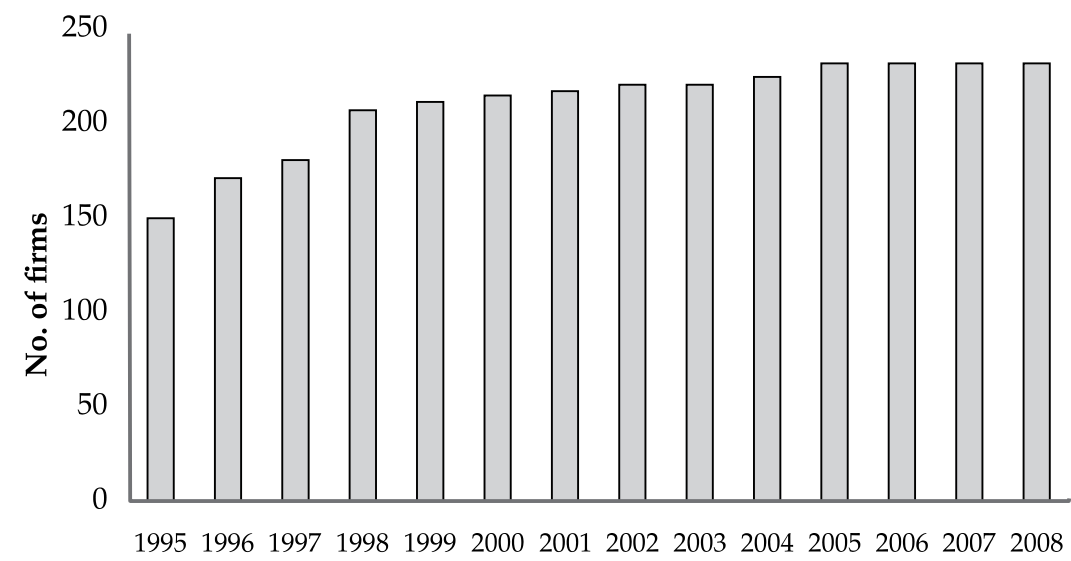

The variables employed include: (i) size, (ii) systematic risk (beta), (iii) book-to-market equity, and (iv) VaR. These are explained below.

Following the literature, we measure firm size using the natural logarithm of the market value of equity, i.e., the stock price multiplied by the number of shares outstanding as of the sample selection date (each December).

In constructing systematic risk (beta), we follow Fama and French (1992) and sort all the sample stocks by size to determine the KSE size quintile breakpoints, based on which the stocks are allocated into five size portfolios. We then subdivide each size quintile into another five portfolios based on pre-ranking betas for all the sample stocks. The preranking betas are calculated using two to five years' (as available) data on the monthly returns ending in December of year $t$ based on the market model. In all, 162 post-ranking monthly returns for each of the 25 portfolios are computed for the period January 1995 to June 2008. 
Following Fama and French (1992), we estimate the pre-ranking betas as the sum of the slopes yielded by regressing the monthly return on the current and previous months' market returns:

$$
R_{j t}=\beta_{0 j}+\beta_{1 j} R_{m t}+\beta_{2 j} R_{m t-1}+u_{j t}
$$

where $R_{j t}$ is the monthly return on stock $j$ in period $t, \beta_{1 j}+\beta_{2 j}$ is the preranking beta for stock $j, R_{m t}$ is the monthly return on the KSE valueweighted index in period $t$, and $u_{j t}$ is the residual series from the time series regression.

Book-to-market equity or $\mathrm{BE} / \mathrm{ME}$ is the ratio of the book value of equity plus deferred taxes to the market value of equity. This study uses each firm's market price and equity data as of the end of December for each year to compute its BE/ME. Given the absence of reliable historical data on book values, we have employed December 2000 values (which fall roughly in between the sample period) to construct book-to-market portfolios.

In order to construct portfolios sorted by $\mathrm{VaR}$, we sort the sample stocks by 99, 95, and 90 percent $\mathrm{VaR}$ levels and obtain the average returns and average $\mathrm{VaR}$ for each decile portfolio. The VaR is estimated using the historical simulation method. ${ }^{3}$ The mean and cutoff return for each confidence level is estimated using 24-60 monthly returns (as available). The 99, 95, and 90 percent confidence level VaRs are then measured by the lowest, third lowest, and sixth lowest observations drawn from these monthly returns in December of each year, starting from 1995.

\section{Methodology}

This section explains how the relationship between $\mathrm{VaR}$ and expected returns is determined.

\subsection{VaR and the Cross-Section of Expected Returns}

In order to capture the relationship between $\mathrm{VaR}$ and expected returns, we investigate whether stock portfolios with a higher maximum likely loss (as measured by VaR) earn higher expected returns. Starting from 1995 through December of each subsequent year, we sort the sample of $232 \mathrm{KSE}$ stocks by 99,95 , and 90 percent VaR levels to determine the

\footnotetext{
${ }^{3}$ There are several parametric and nonparametric methods of estimating VaR; see Iqbal, Azher, and Ijaz (2013) for a comparison of predictive abilities. Examining the sensitivity of the study's results to different $\mathrm{VaR}$ estimates could be an interesting direction for future research.
} 
decile breakpoint for each VaR stock. Based on these breakpoints, we then allocate the stocks among 99, 95, and 90 percent VaR deciles. Decile 1 comprises the 10 percent of stocks with the lowest VaR; decile 10 represents those stocks with the highest VaR. We also compute the equally weighted average returns for the stocks in each decile. The portfolios are rebalanced every December for the subsequent years.

\subsection{VaR and Time Series Variations in Expected Returns}

Given the drawbacks of the CAPM, Fama and French (1992) have developed an alternative asset-pricing model, which we employ to study the usefulness of the VaR factor. Fama and French (1993) study the common risk factors in stock returns using six portfolios formed by sorting the stocks by size (ME) and BE/ME. Following this method, we rank the 232 sample stocks for January of each year $t$ from 1995 to June 2008 according to size. The median stock size is used to divide the stocks into two groups: small (S) and big (B). The stocks are sorted separately into three portfolios based on the breakpoints for the bottom 30 percent (L), the middle 40 percent $(\mathrm{M})$, and the top 30 percent $(\mathrm{H})$. Thus, we construct six portfolios (S/L, S/M, S/H, B/L, B/M, and B/H) from the intersection of the two $\mathrm{ME}$ groups and the three $\mathrm{BE} / \mathrm{ME}$ groups.

The Fama and French small-minus-big (SMB) factor is constructed as the difference between the average return on a portfolio of three smallcap stocks, i.e., $(\mathrm{S} / \mathrm{L}+\mathrm{S} / \mathrm{M}+\mathrm{S} / \mathrm{H}) / 3$, and the average return on a portfolio of three big-cap stocks, i.e., $(B / L+B / M+B / H) / 3$. The highminus-low (HML) factor is constructed as the difference between the average return on two high-BE/ME portfolios, i.e., $(\mathrm{S} / \mathrm{H}+\mathrm{B} / \mathrm{H}) / 2$, and the average return on two low-BE /ME portfolios, i.e., $(\mathrm{S} / \mathrm{L}+\mathrm{B} / \mathrm{L}) / 2$.

Following Fama and French (1993, 1995, 1996), we use the excess market return over the risk-free return (RM-RF) as a measure of the market factor in stock returns. The RF is constructed using the 30-day repo rate obtained from DataStream. The excess returns on the 25 portfolios sorted by size and $\mathrm{BE} / \mathrm{ME}$ are employed as dependent variables in the time series regressions.

In order to examine the empirical performance of VaR based on the 25 Fama and French (1993) portfolios, we follow Bali and Cakici (2004) and construct an HVaRL factor (high VaR minus low VaR), which is meant to mimic the risk factor in returns related to $\mathrm{VaR}$ and is defined as the difference between the simple average of the returns on high VaR and low VaR portfolios. The construction of the 95 percent VaR portfolios 
is similar to that of Fama and French's size portfolios: for December of each year $t$ from 1995 through June 2008, we rank 232 stocks by their 95 percent VaR level. The median 95 percent $\mathrm{VaR}$ is used to divide the selected stocks into two groups: high VaR and low VaR.

\subsection{Regression Analysis With Several Factors}

We carry out a series of regressions to ascertain the role of the various factors (RM-RF, SMB, HML, and $H V a R L)$ in explaining returns. These include (i) one-factor models (which use RM-RF, SMB, HML, or HVaRL as a single explanatory variable at a time), (ii) two-factor models (which use RM-RF along with SMB, HML, or HVaRL), (iii) three-factor models (which use RM-RF along with SMB and HML, or SMB and HVaRL, or HML and HVaRL), and (iv) four-factor models (which use RM-RF, SMB, HML, and HVaRL).

\section{Empirical Results}

This section presents the results of each regression analysis.

\subsection{VaR and the Cross-Section of Expected Returns}

Table 1 presents the average returns on the VaR portfolios for all ten deciles as well as the estimated regression coefficients $\hat{\alpha}$ and $\hat{\beta}$, corresponding t-statistics, and $\mathrm{R}^{2}$ values. The cross-sectional regression of average portfolio returns on the average $\mathrm{VaR}$ of the portfolios is given as:

$$
\begin{aligned}
& R_{j}=\alpha+\beta V a R_{j}+u_{j} \\
& j=1,2, \ldots 10
\end{aligned}
$$

As Table 1 shows, when portfolios are formed according to their 99, 95, and 90 percent $\mathrm{VaR}$, average stock returns are positively correlated with VaR. In other words, stocks with a higher maximum likely loss (measured by VaR) generally yield higher average returns. From the lowest to the highest 1 percent $\mathrm{VaR}$ decile, the monthly average return on $\mathrm{VaR}$ portfolios increases from 0.96 to 7.83 percent, which amounts to an 82.45 percent annual return differential. This increase is not monotonic: for example, moving from the eighth to the ninth decile portfolio using the 99 percent $\mathrm{VaR}$ results in a lower average return.

The overall evidence supporting a positive risk-return relationship is fairly strong. This is in contrast to Bali and Cakici (2004) 
who estimate an annual return differential of only 11.52 percent between the highest and lowest VaR portfolios. Our result is, however, consistent with the general observation that emerging markets yield higher returns than developed markets. The result is also important from an investment allocation perspective.

We find a similarly strong positive relationship between average returns and $\mathrm{VaR}$, using the 95 and 90 percent confidence levels. The results show that, the greater a portfolio's potential losses as captured by $\mathrm{VaR}$, the higher will be the expected return. Portfolios of higher-VaR stocks appear to yield higher returns than lower-VaR portfolios.

To gauge the statistical significance of the relationship between the average $\mathrm{VaR}$ and average returns on the $\mathrm{VaR}$ portfolios, we regress the average returns from the decile portfolios on the average $\mathrm{VaR}$ for the 99,95 , and 90 percent levels, respectively. The results indicate that the VaR coefficients are highly significant with a theoretically consistent positive sign. The $\mathrm{R}^{2}$ values range from 83 to 86 percent.

Table 1: Average monthly portfolio returns, August 1992-June 2008

\begin{tabular}{lcccccc}
\hline Decile & 99\% VaR & Return \% & 95\% VaR & Return \% & 90\% VaR & Return \% \\
\hline Low VaR & 2.85 & 0.96 & 0.32 & 1.03 & 0.74 & 1.66 \\
2 & 17.72 & 2.39 & 10.85 & 3.42 & 5.88 & 0.82 \\
3 & 21.67 & 4.07 & 13.95 & 1.92 & 9.13 & 4.08 \\
4 & 25.16 & 3.73 & 16.03 & 2.88 & 11.08 & 3.65 \\
5 & 28.57 & 3.38 & 17.87 & 4.74 & 12.59 & 4.03 \\
6 & 31.89 & 5.23 & 20.36 & 5.57 & 14.10 & 4.32 \\
7 & 35.44 & 5.14 & 22.48 & 5.43 & 16.09 & 4.46 \\
8 & 40.45 & 5.89 & 25.34 & 5.47 & 18.20 & 6.62 \\
9 & 47.64 & 4.68 & 28.62 & 6.19 & 20.64 & 6.39 \\
High VaR & 60.68 & 7.83 & 34.76 & 6.48 & 24.51 & 7.09 \\
\hline Coefficient & $\hat{\alpha}$ & $\hat{\beta}$ & $\hat{\alpha}$ & $\hat{\beta}$ & $\hat{\alpha}$ & $\hat{\beta}$ \\
& 0.93 & 0.11 & 0.94 & 0.18 & 0.75 & 0.27 \\
t-statistic & $2.45^{* *}$ & $8.04^{*}$ & $1.95^{* * *}$ & $9.79^{*}$ & 1.07 & $6.76^{*}$ \\
$\mathrm{R}^{2}$ & 0.86 & & 0.83 & & 0.86 & \\
\hline
\end{tabular}

Note: ${ }^{*}{ }^{* *}$, and ${ }^{* *}=$ significant at 1,5 , and 10 percent, respectively. We obtain $\mathrm{R}^{2}$ by regressing a cross-section of the average returns to the ten deciles on a constant and the average VaR of the portfolios. The t-statistics are based on heteroskedasticity-consistent standard errors and tested to determine if the estimated coefficients are significantly different from 0.

Source: Authors' calculations. 


\subsection{VaR and Time Series Variations in Expected Stock Returns}

Panel A of Table 2 provides some descriptive statistics for RM-RF, SMB, HML, and HVaRL at a 95 percent confidence level. The normality of the Fama-French and $\mathrm{VaR}$ factors is rejected in all cases. However, the time series sample is large enough to justify statistical tests asymptotically.

Panel B calculates the correlation between RM-RF, SMB, HML, and HVaRL in order to determine the direction and magnitude of the relationship between HVaRL and the three Fama-French factors. There is a positive correlation of 0.59 and 0.53 between the market and HVaRL factors and between HML and HVaRL, respectively. The size factors, however, are weak correlates of HVaRL. Overall, the correlation between HVaRL and the Fama-French factors is not very large, making it possible to estimate any independent influence on portfolio returns without fear of collinearity.

Table 2: Descriptive statistics and Pearson correlation coefficients for HVaRL and Fama-French factors

\begin{tabular}{lcccc}
\hline & \multicolumn{4}{c}{ Descriptive statistics } \\
\cline { 2 - 5 } Panel A & RM-RF & SMB & HML & HVaRL \\
\hline Observations & 162 & 162 & 162 & 162 \\
Mean & 0.003 & -0.007 & -0.006 & -0.011 \\
Median & 0.006 & -0.008 & -0.005 & -0.016 \\
Maximum & 0.240 & 0.126 & 0.186 & 0.217 \\
Minimum & -0.416 & -0.162 & -0.135 & -0.142 \\
Standard deviation & 0.097 & 0.046 & 0.048 & 0.052 \\
Skewness & -0.510 & -0.010 & 0.294 & 0.730 \\
Kurtosis & 4.800 & 3.943 & 4.579 & 5.450 \\
\hline & \multicolumn{5}{c}{ Pearson correlation coefficients } \\
Panel B & HVaRL & RM-RF & SMB & HML \\
\hline HVaRL & 1.000 & \multicolumn{3}{c}{} \\
RM-RF & 0.590 & 1.000 & 1.000 & \\
SMB & -0.019 & -0.586 & -0.041 & 1.000 \\
HML & 0.533 & 0.393 &
\end{tabular}

Source: Authors' calculations.

Table 3 shows the correlation between returns for the 25 portfolios and HVaRL, RM-RF, SMB, and HML. RM-RF and HVaRL capture more common variation in stock returns on average than SMB and HML. 
Table 3: Correlation of 25 portfolio returns with RM-RF, SMB, HML, and HVaRL

\begin{tabular}{|c|c|c|c|c|}
\hline Portfolio & HVaRL & RM-RF & SMB & HML \\
\hline S1BM1 & 0.603 & 0.317 & 0.282 & 0.011 \\
\hline S1BM2 & 0.640 & 0.462 & 0.097 & 0.311 \\
\hline S1BM3 & 0.258 & 0.377 & -0.033 & 0.405 \\
\hline S1BM4 & 0.551 & 0.425 & 0.109 & 0.499 \\
\hline S1BM5 & 0.574 & 0.231 & 0.373 & 0.529 \\
\hline S2BM1 & 0.405 & 0.295 & 0.160 & 0.057 \\
\hline S2BM2 & 0.522 & 0.545 & -0.068 & 0.216 \\
\hline S2BM3 & 0.434 & 0.335 & 0.165 & 0.351 \\
\hline S2BM4 & 0.586 & 0.569 & 0.010 & 0.396 \\
\hline S2BM5 & 0.745 & 0.521 & -0.002 & 0.576 \\
\hline S3BM1 & 0.482 & 0.558 & -0.250 & 0.236 \\
\hline S3BM2 & 0.382 & 0.493 & -0.117 & 0.230 \\
\hline S3BM3 & 0.512 & 0.514 & -0.082 & 0.274 \\
\hline S3BM4 & 0.694 & 0.685 & -0.168 & 0.462 \\
\hline S3BM5 & 0.730 & 0.718 & -0.286 & 0.580 \\
\hline S4BM1 & 0.566 & 0.521 & -0.094 & 0.294 \\
\hline S4BM2 & 0.633 & 0.589 & -0.198 & 0.500 \\
\hline S4BM3 & 0.497 & 0.596 & -0.266 & 0.384 \\
\hline S4BM4 & 0.658 & 0.673 & -0.221 & 0.508 \\
\hline S4BM5 & 0.746 & 0.830 & -0.482 & 0.555 \\
\hline S5BM1 & 0.301 & 0.573 & -0.510 & -0.013 \\
\hline S5BM2 & 0.611 & 0.820 & -0.460 & 0.282 \\
\hline S5BM3 & 0.592 & 0.903 & -0.541 & 0.378 \\
\hline S5BM4 & 0.562 & 0.759 & -0.394 & 0.317 \\
\hline S5BM5 & 0.654 & 0.942 & -0.573 & 0.491 \\
\hline Average & 0.557 & 0.570 & -0.142 & 0.353 \\
\hline
\end{tabular}

Note: S1BM1 denotes a portfolio that belongs to the smallest size quintile and the lowest $\mathrm{BE} / \mathrm{ME}$ quintile. The other portfolios are similarly labeled.

Source: Authors' calculations.

\subsection{Regression Analysis With Several Factors}

This section presents the results of the four- and three-factor models (see Appendix 2 for the results of the one- and two-factor models). 


\subsubsection{Four-Factor Model}

Table 4 presents the parameter estimates, averages, $t$-statistics, adjusted $\mathrm{R}^{2}$ values, and standard errors of estimates for the time series regression of excess stock returns on the four factors RM-RF, SMB, HML, and HVaRL (with a 95 percent confidence level).

Table 4: Four-factor model: Regression of excess stock returns on RMRF, SMB, HML, and HVaRL

$\mathrm{BE} / \mathrm{ME}$ quintile

\begin{tabular}{|c|c|c|c|c|c|c|c|c|c|c|}
\hline Size quintile & Low & 2 & 3 & 4 & High & Low & 2 & 3 & 4 & High \\
\hline & \multicolumn{5}{|c|}{ RM-RF slope (average $=0.485$ ) } & \multicolumn{5}{|c|}{ t-statistics } \\
\hline Small & $0.562^{*}$ & $0.518^{*}$ & $0.680^{*}$ & $0.476^{*}$ & $0.424^{*}$ & 6.01 & 4.84 & 4.94 & 4.66 & 3.32 \\
\hline 2 & $0.437^{*}$ & $0.588^{*}$ & $0.366^{*}$ & $0.581^{*}$ & $0.302^{*}$ & 4.56 & 6.27 & 4.78 & 7.45 & 2.78 \\
\hline 3 & $0.372^{*}$ & $0.531^{*}$ & $0.443^{*}$ & $0.517^{*}$ & $0.407^{*}$ & 3.97 & 5.49 & 4.92 & 6.66 & 4.77 \\
\hline 4 & $0.349^{*}$ & $0.235^{*}$ & $0.331^{*}$ & $0.408^{*}$ & $0.495^{*}$ & 4.13 & 3.20 & 4.45 & 5.41 & 6.16 \\
\hline \multirow[t]{2}{*}{ Big } & $0.413^{*}$ & $0.577^{*}$ & $0.732^{*}$ & $0.564^{*}$ & $0.846^{*}$ & 3.78 & 8.86 & 13.26 & 7.45 & 17.98 \\
\hline & \multicolumn{5}{|c|}{ HVaRL slope (average $=0.432$ ) } & & & & & \\
\hline Small & $1.167^{*}$ & $0.793^{*}$ & $-0.547^{* *}$ & 0.245 & $0.634^{*}$ & 7.87 & 4.67 & -2.51 & 1.51 & 3.14 \\
\hline 2 & $0.354^{* *}$ & $0.335^{* *}$ & 0.061 & 0.191 & $1.117^{*}$ & 2.33 & 2.25 & 0.51 & 1.55 & 6.49 \\
\hline 3 & $0.391^{* *}$ & 0.018 & $0.316^{* *}$ & $0.521^{*}$ & $0.779 *$ & 2.63 & 0.12 & 2.22 & 4.23 & 5.76 \\
\hline 4 & $0.460^{*}$ & $0.460^{*}$ & 0.193 & $0.415^{*}$ & $1.148^{*}$ & 3.44 & 3.95 & 1.64 & 3.47 & 9.00 \\
\hline \multirow[t]{2}{*}{ Big } & $0.421^{* *}$ & $0.463^{*}$ & $0.219^{* *}$ & $0.305^{* *}$ & $0.370^{*}$ & 2.43 & 4.48 & 2.51 & 2.54 & 4.96 \\
\hline & \multicolumn{5}{|c|}{ SMB slope (average $=0.328$ ) } & & & & & \\
\hline Small & $1.327^{*}$ & $0.861^{*}$ & $0.772^{*}$ & $0.830^{*}$ & $1.658^{*}$ & 8.42 & 4.77 & 3.33 & 4.82 & 7.72 \\
\hline 2 & $0.796^{*}$ & $0.593^{*}$ & $0.685^{*}$ & $0.734^{*}$ & $0.412^{* *}$ & 4.93 & 3.75 & 5.31 & 5.59 & 2.25 \\
\hline 3 & 0.028 & $0.450^{*}$ & $0.409^{*}$ & $0.337^{* *}$ & -0.111 & 0.18 & 2.76 & 2.70 & 2.58 & -0.77 \\
\hline 4 & $0.283^{* *}$ & 0.007 & 0.033 & 0.143 & $-0.762^{*}$ & 1.99 & 0.06 & 0.27 & 1.13 & -5.62 \\
\hline \multirow[t]{2}{*}{ Big } & $-0.616^{*}$ & -0.124 & -0.15 & -0.003 & $-0.360^{*}$ & -3.34 & -1.14 & -1.62 & -0.02 & -4.55 \\
\hline & \multicolumn{5}{|c|}{ HML slope (average $=0.084)$} & & & & & \\
\hline Small & $-1.040^{*}$ & -0.16 & $0.753^{*}$ & $0.505^{*}$ & $0.866^{*}$ & -8.14 & -1.09 & 4.00 & 3.62 & 4.97 \\
\hline 2 & $-0.418^{*}$ & $-0.247^{* * *}$ & $0.183^{* * *}$ & 0.098 & $0.592^{*}$ & -3.20 & -1.93 & 1.76 & 0.92 & 4.00 \\
\hline 3 & -0.119 & -0.028 & -0.066 & 0.142 & $0.499^{*}$ & -0.94 & -0.22 & -0.54 & 1.34 & 4.28 \\
\hline 4 & -0.072 & $0.294^{*}$ & $0.170^{* * *}$ & $0.289^{*}$ & $0.493^{*}$ & -0.63 & 2.93 & 1.68 & 2.81 & 4.49 \\
\hline \multirow[t]{2}{*}{ Big } & $-0.614^{*}$ & $-0.230^{* *}$ & 0.005 & -0.074 & $0.283^{*}$ & -4.11 & -2.59 & 0.07 & -0.72 & 4.40 \\
\hline & \multicolumn{5}{|c|}{ Adjusted $R^{2}$ (average $\left.=0.518\right)$} & \multicolumn{5}{|c|}{ SSE } \\
\hline Small & 0.642 & 0.484 & 0.262 & 0.441 & 0.574 & 0.06 & 0.07 & 0.10 & 0.07 & 0.09 \\
\hline 2 & 0.296 & 0.411 & 0.323 & 0.509 & 0.613 & 0.07 & 0.07 & 0.05 & 0.05 & 0.08 \\
\hline 3 & 0.340 & 0.277 & 0.350 & 0.614 & 0.686 & 0.07 & 0.07 & 0.06 & 0.05 & 0.06 \\
\hline 4 & 0.377 & 0.488 & 0.397 & 0.571 & 0.833 & 0.06 & 0.05 & 0.05 & 0.05 & 0.06 \\
\hline Big & 0.430 & 0.711 & 0.822 & 0.593 & 0.920 & 0.08 & 0.05 & 0.04 & 0.05 & 0.03 \\
\hline
\end{tabular}

Note: ${ }^{*}{ }^{* *}$, and ${ }^{* *}=$ significant at 1,5 , and 10 percent, respectively. The table reports statistics for the period January 1995 to June 2008.

Source: Authors' calculations. 
The table shows that the slope coefficients of RM-RF are positive and highly significant (with p-values of less than 0.01). It is worth noting that 22 of the 25 slopes for HVaRL are significant and, barring one, all have the correct positive sign. Ten of these slopes are significant at 1 percent, especially for the largest book-to-market quintile portfolios. The number of significant coefficients corresponding to HVaRL is higher than those for the size and book-to-market factors; its average coefficient is also much larger. The four-factor model yields a greater average adjusted $\mathrm{R}^{2}$ value (0.518) than the other models.

These results are in line with the findings of Bali and Cakici (2004). The smaller size portfolios appear to be strongly related to average portfolio returns compared to portfolios comprising larger sizes. Thus, smaller firms may require higher returns for the greater risk with which they are associated. The signs of the HML factor are not stable.

\subsubsection{Three-Factor Model}

In order to gauge the importance of the $\mathrm{VaR}$ factor, we consider if it can serve as a substitute for any of the Fama-French factors. Tables 5, 6, and 7 present panel estimates from the three-factor model in which the excess returns on 25 portfolios were regressed on RM-RF along with (i) SMB and HML, (ii) HVaRL and SMB, or (iii) HVaRL and HML.

Table 5 indicates that all the RM-RF coefficients are highly significant. The size and book-to-market factors follow in importance with fewer significant coefficients. The average adjusted $\mathrm{R}^{2}$ value is 0.485 , which is slightly lower than that for the four-factor model, including VaR.

Compared to HML, most of the SMB slope coefficients are statistically significant, implying strong size effects but slightly weak book-to-market effects during the testing period; this is consistent with Chen et al. (2009). Once SMB and HML are added to the one-factor model, the average adjusted $\mathrm{R}^{2}$ value increases from 0.359 (Table A1 in Appendix 2) to 0.485 (Table 5), which shows that the factors SMB and HML also help explain the time series variation. These findings are consistent with Fama and French (1993), Al-Mwalla (2012), Al-Mwalla and Karasneh (2011), and Mirza (2008). 
Table 5: Three-factor model: Regression of excess stock returns on RMRF, SMB, and HML (panel A)

\begin{tabular}{|c|c|c|c|c|c|c|c|c|c|c|}
\hline \multirow{2}{*}{ Size quintile } & \multicolumn{10}{|c|}{$\mathrm{BE} / \mathrm{ME}$ quintile } \\
\hline & Low & 2 & 3 & 4 & High & Low & 2 & 3 & 4 & High \\
\hline & \multicolumn{5}{|c|}{ RM-RF slope (average $=0.656)$} & \multicolumn{5}{|c|}{ t-statistics } \\
\hline Small & $1.023^{*}$ & $0.831^{*}$ & $0.464^{*}$ & $0.573^{*}$ & $0.674^{*}$ & 11.89 & 9.34 & 4.25 & 7.15 & 6.58 \\
\hline 2 & $0.577^{*}$ & $0.720^{*}$ & $0.390^{*}$ & $0.656^{*}$ & $0.742^{*}$ & 7.60 & 9.71 & 6.54 & 10.73 & 7.80 \\
\hline 3 & $0.526^{*}$ & $0.539^{*}$ & $0.567^{*}$ & $0.723^{*}$ & $0.714^{*}$ & 7.06 & 7.15 & 7.97 & 11.33 & 9.76 \\
\hline 4 & $0.530^{*}$ & $0.416^{*}$ & $0.407^{*}$ & $0.571^{*}$ & $0.948^{*}$ & 7.79 & 6.94 & 6.98 & 9.38 & 12.29 \\
\hline \multirow[t]{2}{*}{ Big } & $0.579 *$ & $0.760^{*}$ & $0.818^{*}$ & $0.685^{*}$ & $0.993^{*}$ & 6.67 & 14.10 & 18.68 & 11.38 & 25.18 \\
\hline & \multicolumn{5}{|c|}{ SMB slope (average $=0.534$ ) } & & & & & \\
\hline Small & $1.880^{*}$ & $1.237^{*}$ & $0.513^{* *}$ & $0.946^{*}$ & 1.9 & 11.33 & 7.20 & 2.43 & 6.12 & 9.91 \\
\hline 2 & $0.963^{*}$ & $0.752^{*}$ & $0.714^{*}$ & $0.825^{*}$ & $0.942^{*}$ & 6.58 & 5.25 & 6.20 & 6.99 & 5.13 \\
\hline 3 & 0.213 & $0.459^{*}$ & $0.559^{*}$ & $0.585^{*}$ & $0.258^{* * *}$ & 1.49 & 3.16 & 4.07 & 4.75 & 1.83 \\
\hline 4 & $0.501^{*}$ & $0.225^{* * *}$ & 0.125 & $0.339^{*}$ & -0.217 & 3.82 & 1.95 & 1.11 & 2.89 & -1.46 \\
\hline \multirow[t]{2}{*}{ Big } & $-0.416^{* *}$ & 0.094 & -0.046 & 0.141 & $-0.184^{* *}$ & -2.49 & 0.91 & -0.55 & 1.22 & -2.43 \\
\hline & \multicolumn{5}{|c|}{ HML slope (average $=0.207$ ) } & & & & & \\
\hline Small & $-0.706^{*}$ & 0.067 & $0.596^{*}$ & $0.575^{*}$ & $1.048^{*}$ & -4.98 & 0.46 & 3.31 & 4.35 & 6.21 \\
\hline 2 & $-0.317^{* *}$ & -0.151 & $0.201^{* *}$ & 0.152 & $0.912^{*}$ & -2.53 & -1.24 & 2.05 & 1.51 & 5.81 \\
\hline 3 & -0.007 & -0.023 & 0.023 & $0.291^{*}$ & $0.722^{*}$ & -0.06 & -0.19 & 0.20 & 2.77 & 5.99 \\
\hline 4 & 0.059 & $0.426^{*}$ & $0.226^{* *}$ & $0.408^{*}$ & $0.822^{*}$ & 0.53 & 4.30 & 2.35 & 4.07 & 6.47 \\
\hline \multirow[t]{2}{*}{ Big } & $-0.493^{*}$ & -0.097 & 0.068 & 0.012 & $0.389^{*}$ & -3.45 & -1.10 & 0.95 & 0.13 & 5.98 \\
\hline & \multicolumn{5}{|c|}{ Adjusted $R^{2}$ (average $=0.485$ ) } & \multicolumn{5}{|c|}{ SSE } \\
\hline SMllant & 0.504 & 0.416 & 0.237 & 0.436 & 0.550 & 0.08 & 0.08 & 0.10 & 0.07 & 0.09 \\
\hline 2 & 0.276 & 0.396 & 0.327 & 0.505 & 0.512 & 0.07 & 0.07 & 0.05 & 0.05 & 0.08 \\
\hline 3 & 0.316 & 0.282 & 0.334 & 0.572 & 0.622 & 0.07 & 0.07 & 0.06 & 0.06 & 0.07 \\
\hline 4 & 0.334 & 0.440 & 0.391 & 0.541 & 0.749 & 0.06 & 0.05 & 0.05 & 0.05 & 0.07 \\
\hline Big & 0.412 & 0.676 & 0.816 & 0.579 & 0.908 & 0.08 & 0.05 & 0.04 & 0.05 & 0.04 \\
\hline
\end{tabular}

Note: ${ }^{*} * *$, and ${ }^{* * *}=$ significant at 1,5 , and 10 percent, respectively. The table reports statistics for the period January 1995 to June 2008.

Source: Authors' calculations.

Table 6 shows that adding HVaRL and SMB to the one-factor model yields significant coefficients for RM-RF, while HVaRL captures slightly more time variation in the test portfolios than SMB. Five of the HVaRL slope coefficients and eight of the SMB slope coefficients are insignificant. All the HVaRL coefficients have the correct positive sign while some of the SMB coefficients have a negative sign. 
Table 6: Three-factor model: Regression of excess stock returns on RMRF, HVaRL, and SMB (panel B)

\begin{tabular}{|c|c|c|c|c|c|c|c|c|c|c|}
\hline & & & & & & & & & $M$ & n \\
\hline Size quintile & Low & 2 & 3 & 4 & High & Low & 2 & 3 & 4 & High \\
\hline & & M-RF slo & pe (aver & age $=0.4$ & & & & -statisti & & \\
\hline Small & $0.465^{*}$ & $0.503^{*}$ & $0.751^{*}$ & $0.524^{*}$ & $0.505^{*}$ & 4.21 & 4.74 & 5.25 & 4.98 & 3.72 \\
\hline 2 & $0.398^{*}$ & $0.565^{*}$ & $0.383^{*}$ & $0.590^{*}$ & $0.357^{*}$ & 4.07 & 6.02 & 5.01 & 7.63 & 3.17 \\
\hline 3 & $0.361^{*}$ & $0.529^{*}$ & $0.436^{*}$ & $0.531^{*}$ & $0.453^{*}$ & 3.89 & 5.52 & 4.90 & 6.87 & 5.09 \\
\hline 4 & $0.342^{*}$ & $0.262^{*}$ & $0.347^{*}$ & $0.435^{*}$ & $0.541^{*}$ & 4.10 & 3.52 & 4.68 & 5.69 & 6.41 \\
\hline Big & $0.355^{*}$ & $0.555^{*}$ & $0.732^{*}$ & $0.557^{*}$ & $0.873^{*}$ & 3.12 & 8.45 & 13.42 & 7.43 & 17.70 \\
\hline & & VaRL slo & pe (aver & age $=0.4$ & & & & & & \\
\hline Small & $0.765^{*}$ & $0.731^{*}$ & -0.256 & $0.440^{*}$ & $0.969^{*}$ & 4.60 & 4.56 & -1.19 & 2.78 & 4.74 \\
\hline 2 & 0.192 & $0.239^{* * *}$ & 0.132 & $0.229^{* * *}$ & $1.346^{*}$ & 1.30 & 1.69 & 1.15 & 1.96 & 7.93 \\
\hline 3 & $0.345^{* *}$ & 0.007 & $0.291^{* *}$ & $0.576^{*}$ & $0.972^{*}$ & 2.46 & 0.05 & 2.16 & 4.95 & 7.23 \\
\hline 4 & $0.433^{*}$ & $0.574^{*}$ & $0.259^{* *}$ & $0.527^{*}$ & $1.338^{*}$ & 3.44 & 5.10 & 2.32 & 4.57 & 10.50 \\
\hline Big & 0.183 & $0.374^{*}$ & $0.221^{*}$ & $0.276^{* *}$ & $0.480^{*}$ & 1.07 & 3.77 & 2.69 & 2.45 & 6.45 \\
\hline & & MB slop & e (avera & ge $=0.33$ & & & & & & \\
\hline Small & $1.241^{*}$ & $0.848^{*}$ & $0.834^{*}$ & $0.871^{*}$ & $1.729^{*}$ & 6.64 & 4.71 & 3.44 & 4.89 & 7.52 \\
\hline 2 & $0.761^{*}$ & $0.572^{*}$ & $0.700^{*}$ & $0.743^{*}$ & $0.460^{* *}$ & 4.60 & 3.60 & 5.40 & 5.67 & 2.41 \\
\hline 3 & 0.018 & $0.448^{*}$ & $0.403^{*}$ & $0.349^{*}$ & -0.070 & 0.12 & 2.76 & 2.67 & 2.67 & -0.47 \\
\hline 4 & $0.277^{* * *}$ & 0.031 & 0.047 & 0.166 & $-0.721^{*}$ & 1.96 & 0.25 & 0.38 & 1.29 & -5.04 \\
\hline Big & $-0.666^{*}$ & -0.143 & -0.150 & -0.009 & $-0.337^{*}$ & $\begin{array}{l}- \\
3.46 \\
\end{array}$ & $\begin{array}{l}- \\
1.29 \\
\end{array}$ & -1.62 & $\begin{array}{l}- \\
0.07 \\
\end{array}$ & -4.04 \\
\hline & & djusted & $2^{2}$ (aver & ge $=0.49$ & & & & SSE & & \\
\hline Small & 0.494 & 0.483 & 0.191 & 0.398 & 0.510 & 0.08 & 0.07 & 0.10 & 0.07 & 0.10 \\
\hline 2 & 0.254 & 0.401 & 0.314 & 0.509 & 0.576 & 0.07 & 0.07 & 0.05 & 0.05 & 0.08 \\
\hline 3 & 0.341 & 0.281 & 0.353 & 0.612 & 0.651 & 0.07 & 0.07 & 0.06 & 0.05 & 0.06 \\
\hline 4 & 0.380 & 0.463 & 0.390 & 0.552 & 0.813 & 0.06 & 0.05 & 0.05 & 0.05 & 0.06 \\
\hline Big & 0.373 & 0.701 & 0.823 & 0.594 & 0.910 & 0.08 & 0.05 & 0.04 & 0.05 & 0.03 \\
\hline
\end{tabular}

Note: ${ }^{*}{ }^{* *}$, and ${ }^{* * *}=$ significant at 1,5 , and 10 percent, respectively. The table reports statistics for the period January 1995 to June 2008.

Source: Authors' calculations.

Interestingly, in Table 7, HVaRL captures greater time variation than RM-RF and SMB as indicated by their significant coefficients. Only three of the HVaRL coefficients are insignificant compared to five and ten, respectively, in the case of RM-RF and SMB. The average adjusted $\mathrm{R}^{2}$ value is 0.476 . Again, while the HML factor carries both signs, HVaRL has a robust positive sign in all cases. 
Table 7: Three-factor model: Regression of excess stock returns on RMRF, HVaRL, and HML (panel C)

\begin{tabular}{|c|c|c|c|c|c|c|c|c|c|c|}
\hline & & & & & & & & & M & $\mathrm{nt1}$ \\
\hline Size quintile & Low & 2 & 3 & 4 & High & Low & 2 & 3 & 4 & High \\
\hline & & M-RF slo & oe (avera & ge $=0.3$ & & & & statisti & & \\
\hline Small & 0.001 & $0.154^{* * *}$ & $0.353^{*}$ & 0.125 & $-0.277^{*}$ & 0.02 & 1.92 & 3.54 & 1.64 & -2.64 \\
\hline 2 & 0.100 & $0.337^{*}$ & 0.076 & $0.270^{*}$ & 0.127 & 1.40 & 4.92 & 1.31 & 4.52 & 1.65 \\
\hline 3 & $0.360^{*}$ & $0.341^{*}$ & $0.270^{*}$ & $0.374^{*}$ & $0.454^{*}$ & 5.50 & 4.92 & 4.19 & 6.75 & 7.59 \\
\hline 4 & $0.229^{*}$ & $0.232^{*}$ & $0.317^{*}$ & $0.347^{*}$ & $0.818^{*}$ & 3.83 & 4.51 & 6.09 & 6.56 & 13.25 \\
\hline Big & $0.674^{*}$ & $0.630^{*}$ & $0.795^{*}$ & $0.565^{*}$ & $0.999^{*}$ & 8.50 & 13.76 & 20.43 & 10.67 & 28.50 \\
\hline & & VaRL slo & pe (avera & ge $=0.5$ & & & & & & \\
\hline Small & $1.725^{*}$ & $1.155^{*}$ & -0.222 & $0.594^{*}$ & $1.331^{*}$ & 10.82 & 7.12 & -1.10 & 3.84 & 6.28 \\
\hline 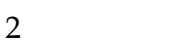 & $0.688^{*}$ & $0.584^{*}$ & $0.349^{*}$ & $0.499^{*}$ & $1.291^{*}$ & 4.72 & 4.22 & 2.97 & 4.14 & 8.27 \\
\hline 3 & $0.403^{*}$ & 0.207 & $0.488^{*}$ & $0.663^{*}$ & $0.732^{*}$ & 3.04 & 1.48 & 3.75 & 5.91 & 6.06 \\
\hline 4 & $0.579^{*}$ & $0.463^{*}$ & $0.207^{* * *}$ & $0.475^{*}$ & $0.828^{*}$ & 4.80 & 4.45 & 1.97 & 4.44 & 6.64 \\
\hline Big & 0.162 & $0.410^{*}$ & $0.156^{* *}$ & $0.304^{*}$ & $0.219^{*}$ & 1.01 & 4.44 & 1.99 & 2.84 & 3.09 \\
\hline & & IML slo & e (aver & $\mathrm{e}=0.10$ & & & & & & \\
\hline Small & $-0.969^{*}$ & -0.113 & 0.79 & $0.550^{*}$ & $0.956^{*}$ & -6.33 & -0.73 & 4.10 & 3.70 & 4.69 \\
\hline & $-0.375^{*}$ & -0.215 & $0.220^{* * *}$ & 0.137 & $0.614^{*}$ & -2.68 & -1.62 & 1.95 & 1.19 & 4.10 \\
\hline & -0.118 & -0.004 & -0.044 & 0.16 & $0.493^{*}$ & -0.93 & -0.03 & -0.36 & 1.49 & 4.25 \\
\hline 4 & -0.056 & $0.294^{*}$ & $0.172^{* * *}$ & $0.297^{*}$ & $0.452^{*}$ & -0.49 & 2.95 & 1.71 & 2.89 & 3.78 \\
\hline Big & $-0.647^{*}$ & $-0.237^{*}$ & -0.002 & -0.074 & $0.263^{*}$ & -4.21 & -2.67 & -0.03 & -0.73 & 3.87 \\
\hline & & djusted I & $2^{2}$ (averag & ge $=0.47$ & & & & SSE & & \\
\hline Small & 0.484 & 0.413 & 0.215 & 0.362 & 0.416 & 0.08 & 0.08 & 0.10 & 0.08 & 0.10 \\
\hline 2 & 0.192 & 0.362 & 0.207 & 0.415 & 0.603 & 0.07 & 0.07 & 0.06 & 0.06 & 0.08 \\
\hline 3 & 0.344 & 0.247 & 0.325 & 0.600 & 0.686 & 0.06 & 0.07 & 0.06 & 0.05 & 0.06 \\
\hline 4 & 0.365 & 0.491 & 0.401 & 0.570 & 0.801 & 0.06 & 0.05 & 0.05 & 0.05 & 0.06 \\
\hline Big & 0.393 & 0.711 & 0.820 & 0.595 & 0.910 & 0.08 & 0.05 & 0.04 & 0.05 & 0.03 \\
\hline
\end{tabular}

Note: ${ }^{*} * *$, and ${ }^{* * *}=$ significant at 1,5 , and 10 percent, respectively. The table reports statistics for the period January 1995 to June 2008.

Source: Authors' calculations.

It is interesting to note that the three-factor model captures slightly more common variation in terms of the adjusted $\mathrm{R}^{2}$ value when using HVaRL with SMB or HML: the average adjusted $\mathrm{R}^{2}$ value increases from 0.485 (Table 5) to 0.494 (Table 6).

\section{Conclusion}

Investigating the asset-pricing implications of $\mathrm{VaR}$ as a risk factor can be a difficult task, especially in the context of emerging markets where economic and political conditions may be volatile. However, VaR is now widely applied in the financial world and is popular among risk managers, banks, and financial institutions that wish to determine 
whether their investors are compensated adequately in terms of high returns. Our main aim has been to investigate the role of $\mathrm{VaR}$ at three different confidence levels (10, 5, and 1 percent) in Pakistan as an emerging market for the period August 1995 to June 2008.

The study compares the explanatory power of $\mathrm{VaR}$ with that of the size and book-to-market factors by adopting both a cross-sectional and time series approach. It also investigates the asset-pricing implications of downside risk as measured by $\mathrm{VaR}$ and examines the cross-section of expected returns for decile portfolios sorted by the VaR $(10,5$, and 1 percent) of each stock. Portfolios with a higher VaR are found to yield a higher average return; the VaR factor thus significantly explains the cross-sectional variations in expected returns. As a measure of downside risk, therefore, $\mathrm{VaR}$ is associated with higher returns.

We also evaluate the performance of $\mathrm{VaR}$ at the portfolio level by using a time series regression approach. This involves applying one-, two-, three-, and four-factor models where the monthly returns associated with a portfolio constructed by sorting stocks with respect to size and book-to-market are regressed on the returns for a market portfolio of stocks as well as size, book-to-market, and VaR factors. Our empirical results show that $\mathrm{VaR}$ captures substantial time variation in stock returns in the one-factor and two-factor models. More importantly, it gains additional explanatory power after controlling for the characteristics of RM-RF, SMB, and HML in the four-factor model.

Overall, our results imply that VaR is better able to capture crosssectional and time series variations than size and book-to-market factors in Pakistan's emerging market. Currently, it is implemented by the State Bank of Pakistan and the Securities and Exchange Commission of Pakistan, primarily to supervise the risk exposure of banks, brokerage houses, and investment companies. Our results suggest that VaR could serve as a useful measure for quantifying the downside risk exposure of equity securities in Pakistan.

The study could be extended to compare VaR with other measures of risk such as beta, downside beta, lower partial moment, and liquidity. In addition, the analysis could be extended to examine the sensitivity of the relationship between expected returns and $\mathrm{VaR}$ to various parametric and nonparametric methods of estimating VaR. 


\section{References}

Al-Mwalla, M. (2012). Can book-to-market, size and momentum be extra risk factors that explain the stocks rate of return? Evidence from emerging market. Journal of Finance, Accounting and Management, $3(2), 42-57$.

Al-Mwalla, M., \& Karasneh, M. (2011). Fama and French three-factor model: Evidence from emerging market. European Journal of Economics, Finance and Administrative Sciences, 41, 132-140.

Ang, A., Chen, J., \& Xing, Y. (2006). Downside risk. Review of Financial Studies, 19(4), 1191-1239.

Bali, T. G., \& Cakici, N. (2004). Value at risk and expected stock returns. Financial Analysts Journal, 60(2), 57-73.

Bali, T. G., Demirtas, K. O., \& Levy, H. (2009). Is there an intertemporal relation between downside risk and expected returns? Journal of Financial and Quantitative Analysis, 44(4), 883-909.

Bali, T. G., Gokcan, S., \& Liang, B. (2007). Value at risk and the crosssection of hedge fund returns. Journal of Banking and Finance, 31(4), 1135-1166.

Banz, R. W. (1981). The relationship between return and market value of common stocks. Journal of Financial Economics, 9, 3-18.

Basu, S. (1977). Investment performance of common stocks in relation to their price-earnings ratios: A test of the efficient market hypothesis. Journal of Finance, 32(3), 663-682.

Bawa, V. S. (1975). Optimal rules for ordering uncertain prospects. Journal of Financial Economics, 2(1), 95-121.

Bawa, V. S., \& Lindenberg, E. B. (1977). Capital market equilibrium in a mean-lower partial moment framework. Journal of Financial Economics, 5(2), 189-200.

Bekaert, G., Erb, C. B., Harvey, C. R., \& Viskanta, T. E. (1998). Distributional characteristics of emerging market returns and asset allocation. Journal of Portfolio Management, 24(3), 102-116. 
Bekaert, G., \& Harvey, C. R. (2002). Research in emerging markets finance: Looking to the future. Emerging Markets Review, 3(4), 429-448.

Bhandari, L. C. (1988). Debt/equity ratio and expected common stock returns: Empirical evidence. Journal of Finance, 43(2), 507-528.

Black, F., Jensen, M. C., \& Scholes, M. (1972). The capital asset pricing model: Some empirical tests. In M. C. Jensen (Ed.), Studies in the theory of capital markets (pp. 79-121). New York, NY: Praeger.

Blitz, D., Pang, J., \& van Vliet, P. (2013). The volatility effect in emerging markets. Emerging Markets Review, 16, 31-45.

Chan, L. K. C., Hamao, Y., \& Lakonishok, J. (1991). Fundamentals and stock returns in Japan. Journal of Finance, 46(5), 1739-1764.

Chen, D.-H., Chen, C.-D., \& Chen, C.-C. (2010, March). VaR and the crosssection of expected stock returns: An emerging market evidence. Paper presented at the Conference of the Southwestern Finance Association, Dallas, TX.

Chung, Y. P., Johnson, H., \& Schill, M. J. (2006). Asset pricing when returns are nonnormal: Fama-French factors versus higher-order systematic co-moments. Journal of Business, 79(2), 923-940.

Claessens, S., Dasgupta, S., \& Glen, J. (1995). Return behavior in emerging stock markets. World Bank Economic Review, 9(1), 131-151.

de Groot, W., Pang, J., \& Swinkels, L. A. P. (2012). The cross-section of stock returns in frontier emerging markets. Journal of Empirical Finance, 19(5), 796-818.

Dittmar, R. F. (2002). Nonlinear pricing kernels, kurtosis preference, and evidence from the cross-section of equity returns. Journal of Finance, 57(1), 369-403.

Eftekhari, B., \& Satchell, S. (1996). Non-normality of returns in emerging markets. Research in International Business and Finance [Supplement], 1, 267-277.

Estrada, J. (2000). The cost of equity in emerging markets: A downside risk approach. Emerging Markets Quarterly, 4(3), 19-30. 
Estrada, J. (2002). Systematic risk in emerging markets: The D-CAPM. Emerging Markets Review, 3, 365-379.

Fama, E. F., \& French, K. (1992). The cross-section of expected stock returns. Journal of Finance, 47(2), 427-465.

Fama, E. F., \& French, K. (1993). Common risk factors in the returns on stocks and bonds. Journal of Financial Economics, 33(1), 3-56.

Fama, E. F., \& French, K. (1995). Size and book-to-market factors in earnings and returns. Journal of Finance, 50(1), 131-155.

Fama, E. F., \& French, K. (1996). Multifactor explanations of asset pricing anomalies. Journal of Finance, 51(1), 55-84.

Fishburn, P. C. (1977). Mean-risk analysis with risk associated with below-target returns. American Economic Review, 67(2), 116-126.

Harlow, W. V., \& Rao, R. K. S. (1989). Asset pricing in a generalized mean-lower partial moment framework: Theory and evidence. Journal of Financial and Quantitative Analysis, 24(3), 285-312.

Harvey, C. R., \& Siddique, A. (2000). Conditional skewness in asset pricing tests. Journal of Finance, 55(3), 1263-1295.

Iqbal, J. (2012). Stock market in Pakistan: An overview. Journal of Emerging Market Finance, 11(1), 61-91.

Iqbal, J., Azher, S., \& Ijaz, A. (2013). Predictive ability of the value-at-risk methods: Evidence from the Karachi Stock Exchange-100 index. IUP Journal of Financial Risk Management, 10(1) 26-40.

Iqbal, J., Brooks, R., \& Galagedera, D. U. (2010). Testing the lower partial moment asset pricing models in emerging markets. In G. N. Gregoriou \& R. Pascalau (Eds.), Financial econometrics modeling: Market microstructure, factor models and financial risk measures (pp. 154-175). Basingstoke: Palgrave Macmillan.

Khawaja, A. I., \& Mian, A. (2005). Unchecked intermediaries: Price manipulation in an emerging stock market. Journal of Financial Economics, 78(1), 203-241. 
Lintner, J. (1969). The aggregation of investor's diverse judgments and preferences in purely competitive security markets. Journal of Financial and Quantitative Analysis, 4(4), 347-400.

Mao, J. C. T. (1970). Models of capital budgeting, E-V vs. E-S. Journal of Financial and Quantitative Analysis, 4(5), 657-676.

Markowitz, H. M. (1952). Portfolio selection. Journal of Finance, 7(1), 77-91.

Markowitz, H. M. (1959). Portfolio selection: Efficient diversification of investments. New York, NY: John Wiley.

Mirza, N. (2008). Size and value premium in Karachi Stock Exchange. Lahore Journal of Economics, 13(2), 1-26.

Nawrocki, D. N. (1999). A brief history of downside risk measures. Journal of Investing, 8(3), 9-25.

Pastor, L., \& Stambaugh, R. F. (2003). Liquidity risk and expected stock returns. Journal of Political Economy, 111(3), 642-685.

Quirk, J. P., \& Saposnik, R. (1962). Admissibility and measurable utility functions. Review of Economic Studies, 29(2), 140-146.

Rosenberg, B., Reid, K., \& Lanstein, R. (1985). Persuasive evidence of market inefficiency. Journal of Portfolio Management, 11(3), 9-17.

Roy, A. D. (1952). Safety first and the holding of assets. Econometrica, 20(3), 431-449.

Sharpe, W. F. (1964). Capital asset prices: A theory of market equilibrium under conditions of risk. Journal of Finance, 19(3), 425-442.

Stattman, D. (1980). Book values and stock returns. The Chicago MBA: A Journal of Selected Papers, 4, 25-45. 


\section{Appendix 1}

\section{List of firms used in the study}

\begin{tabular}{ll}
\hline No. & Firm \\
\hline 1. & Abbott Labs (Pak.) \\
2. & ABN Amro Bank (Pak.) \\
3. & Adamjee Insurance \\
4. & Agriauto Industries \\
5. & Al Abid Silk \\
6. & Al Zamin Leasing Corp. \\
7. & Al-Abbas Cement \\
8. & Al-Ghazi Tractors \\
9. & Al-Khair Gadoon \\
10. & Allied Bank \\
11. & Al-Mazeen Mutual Fund \\
12. & Al-Noor Modaraba Management \\
13. & American Life Insurance \\
14. & Arif Habib Securities \\
15. & Askari Bank \\
16. & Askari Leasing \\
17. & Atlas Honda \\
18. & Atlas Insurance \\
19. & Attock Cement Pakistan \\
20. & Attock Petroleum \\
21. & Attock Refinery \\
22. & Azgard Nine \\
23. & Balochistan Glass \\
24. & Bank Al Habib \\
25. & Bank Al-Falah Limited \\
26. & Bank of Punjab \\
27. & Bannu Woolen Mills \\
28. & Bata Pakistan \\
29. & Bestway Cement \\
30. & Bhanero Textiles \\
31. & BOC Pakistan \\
32. & Bolan Castings \\
\hline
\end{tabular}

No. Firm

33. Bosicor Pakistan

34. Capital Assets Leasing

35. Central Insurance

36. Century Insurance

37. Century Paper

38. Cherat Cement

39. Clariant Pakistan

40. Colgate Palmolive

41. Crescent Commercial Bank

42. Crescent Steel

43. Crescent Textiles

44. D G Khan Cement Company

45. Dadabhoy Cement

46. Dadabhoy Sack

47. Dadex Eternit

48. Dandot Cement

49. Dawood Capital Management

50. Dawood Hercules

51. Dawood Lawrencepur

52. Dewan Automotive Engineering

53. Dewan Cement

54. Dewan Farooque Motors

55. Dewan Mushtaq Textiles

56. Dewan Salman Fiber

57. Dewan Sugar

58. Dewan Textile Mills

59. Dreamworld

60. East West Insurance

61. Ecopack

62. EFU General Insurance

63. EFU Life Assurance

64. English Leasing 


\begin{tabular}{|c|c|c|c|}
\hline No. & Firm & No. & Firm \\
\hline 65. & Engro Chemicals & 101. & Ibrahim Fibers \\
\hline 66. & Escorts Investment Bank & 102. & ICI Pakistan \\
\hline 67. & Faisal Spinning Mills & 103. & Ideal Spinning Mills \\
\hline 68. & Fateh Textile Mills & 104. & Indus Motors \\
\hline 69. & Fauji Cement Limited & 105. & Inter Asia Leasing \\
\hline 70. & Fauji Fertilizer & 106. & International General Insurance \\
\hline 71. & Fauji Fertilizer Bin Qasim & 107. & International Industries \\
\hline 72. & Faysal Bank & 108. & International Multi Leasing \\
\hline 73. & Fazal Textile Mills & 109. & Invest Capital Investment Bank \\
\hline 74. & Fecto Cement & 110. & Investec Mutual Fund \\
\hline 75. & Ferozsons Laboratories & 111. & Investec Securities \\
\hline 76. & First IBL Modaraba & 112. & J K Spinning Mills \\
\hline 77. & First Interfund Modaraba & 113. & J O V \& Co. \\
\hline 78. & First Tristar Mod & 114. & Jahangeer Siddiqui \\
\hline 79. & Gadoon Textiles & 115. & Japan Power Generation \\
\hline 80. & Gammon Pakistan & 116. & Javedan Cement \\
\hline 81. & Gatron Industries & 117. & JDW Sugar Mills \\
\hline 82. & Gauhar Engineering & 118. & JS Global Capital \\
\hline 83. & General Tyre and Rubber Co. & 119. & JS Value Fund \\
\hline 84. & Ghani Glass & 120. & Karachi Electric Supply Corp. \\
\hline 85. & Gharibwal Cement & 121. & Karam Ceramics \\
\hline 86. & Gillette Pakistan & 122. & KASB Modaraba \\
\hline 87. & GlaxoSmithKline Pakistan & 123. & Khalid Siraj Textiles \\
\hline 88. & Gul Ahmed Textile Mills & 124. & Kohat Cement \\
\hline 89. & Gulistan Spinning Mills & 125. & Kohinoor Energy \\
\hline 90. & Gulistan Textile Mills & 126. & Kohinoor Mills \\
\hline 91. & Habib ADM & 127. & Kohinoor Spinning Mills \\
\hline 92. & Habib Metro Bank & 128. & Kohinoor Textile Mills \\
\hline 93. & Habib Modaraba First & 129. & Kot Addu Power \\
\hline 94. & Habib Sugar & 130. & Lakson Tobacco \\
\hline 95. & Hala Enterprises & 131. & Liberty Mills \\
\hline 96. & Hayeri Construct & 132. & Lucky Cement \\
\hline 97. & Hinopak Motors & 133. & Mandviwala Mauser \\
\hline 98. & Honda Atlas Cars & 134. & Maple Leaf Cement \\
\hline 99. & Hub Power & 135. & Mari Gas \\
\hline 100. & Huffaz Seamless Pipe & 136. & MCB Bank \\
\hline
\end{tabular}




\begin{tabular}{|c|c|c|}
\hline No. & Firm & No. $\quad$ Firm \\
\hline 137. & Meezan Bank & 172. Pakistan PTA \\
\hline 138. & Mehmood Textiles & 173. Pakistan Refinery \\
\hline 139. & Millat Tractors & 174. Pakistan Services \\
\hline 140. & Mirpurkhas Sugar & 175. Pakistan State Oil \\
\hline 141. & Modaraba Al-Mal & 176. Pakistan Synthetic \\
\hline 142. & Murree Brewery & 177. Pakistan Tobacco \\
\hline 143. & Mustehkam Cement & 178. Paramount Spinning Mills \\
\hline 144. & MyBank & 179. PICIC Growth Fund \\
\hline 145. & Nakshbandi Industries & 180. PICIC Investment Fund \\
\hline 146. & National Bank of Pakistan & 181. Pioneer Cement \\
\hline 147. & National Refinery & 182. Prudential Dis. House \\
\hline 148. & Nestle Pakistan & 183. PTCLA \\
\hline 149. & New Jubilee Insurance & 184. Quality Textile Mills \\
\hline 150. & New Jubilee Life Insurance & 185. Rafhan Maize Products \\
\hline 151. & NIB Bank & 186. Rupali Polyester \\
\hline 152. & Nimir Industrial Chemicals & 187. S G Fibers \\
\hline 153. & Nishat (Chunian) & 188. Saif Textile Mills \\
\hline 154. & Nishat Mills & 189. Samin Textile Mills \\
\hline 155. & Noon Sugar Mills & 190. Sana Industries \\
\hline 156. & Oil and Gas Development Corp. & 191. Sanofi-Aventis \\
\hline 157. & Orix Investment Bank & 192. Sapphire Fibers \\
\hline 158. & Orix Leasing Pak. & 193. Sapphire Textile Mills \\
\hline 159. & Otsuka Pakistan & 194. Saudi Pak Commercial Bank \\
\hline 160. & Packages & 195. Sazgar Engineering \\
\hline 161. & Pak Elektron & 196. Searle Pakistan \\
\hline 162. & Pak Suzuki Motor & 197. Security Investment Bank \\
\hline 163. & Pakistan Cement & 198. Security Paper \\
\hline 164. & Pakistan Engineering & 199. Service Industries \\
\hline 165. & Pakistan Hotels Dvpr. & 200. Shabir Tiles \\
\hline 166. & Pakistan Insurance & 201. Shadman Cotton Mills \\
\hline 167. & Pakistan International Airlines & 202. Shaffi Chemical Industries \\
\hline \multirow[t]{2}{*}{168.} & Pakistan International Container & 203. Shaheen Insurance \\
\hline & Terminal & 204. Shahtaj Sugar Mills \\
\hline 169. & Pakistan National Shipping & 205. Shakarganj Mills \\
\hline 170. & Pakistan Oilfields & 206. Shell Pakistan \\
\hline 171. & Pakistan Petroleum & 207. Siemens Engineering \\
\hline
\end{tabular}


No. Firm

208. Sitara Chemical Industries

No. Firm

209. Soneri Bank

221. Trust Investment Bank

210. Southern Electric Power

222. Trust Modaraba

211. Standard Chartered Modaraba

223. Unicap Modaraba

212. Sui Northern Gas

224. Unilever Pakistan

213. Sui Southern Gas

225. Unilever Pakistan Foods

214. Sunshine Cotton Mills

226. United Bank

215. Syed Match Co.

227. United Sugar Mills

216. Taj Textile Mills

228. Wazir Ali Industries

217. Telecard

229. Worldcall Telecom

218. Thal

230. Wyeth Pakistan

219. Tri-Pack Films

231. Zeal Pakistan Cement

220. Tri-Star Polyester 


\section{Appendix 2}

\section{Results obtained from one-factor and two-factor models}

\section{One-factor model}

Table A1 gives the estimates and averages obtained from the onefactor model in which the excess returns on 25 portfolios are regressed separately on RM-RF, SMB, HML, and HVaRL. It is evident from the table that, when these factors are employed individually, RM-RF captures more common variation in stock returns than HVaRL, SMB, or HML. All the market slopes are statistically significant. The average slope coefficient of RM-RF is 0.547 . HVaRL captures a greater degree of time series variation in portfolio returns, even when used alone. These findings are consistent with Bali and Cakici (2004) and Chen et al. (2009). All the slope coefficients are statistically significant at the 1 percent level. The average slope of HVaRL is 1.002 and the t-statistics range from 3.38 to 14.14. The average adjusted R-squared value is 0.322 .

The results also show that the portfolios with the highest book-tomarket value are more sensitive to changes in HVaRL and have larger statistically significant coefficients than the other portfolios. Relative to the other factors, HVaRL has a higher degree of explanatory power for the portfolios in the large-cap stock quintile than SMB and HML. Specifically, the average adjusted R-squared value for $\mathrm{HVaRL}$ is 0.322 while the corresponding range for SMB and HML is 0.078-0.148, respectively.

$\mathrm{SMB}$, which mimics the factor in returns related to size, has less explanatory power than HVaRL and HML. Nine of the slope coefficients are statistically insignificant and 18 of the adjusted R-squared values are less than 0.1. As expected, the SMB slopes are related to size: in every $\mathrm{BE} / \mathrm{ME}$ for $\mathrm{SMB}$, the slopes generally decrease from smaller to larger size quintiles. HML, when used alone, explains the large difference in contrast to SMB: three of its slope coefficients are statistically insignificant and 11 of the adjusted R-squared values are less than 0.1. Clearly, the slopes for HML are systematically related to BE/ME. In every size quintile of stocks, the HML slopes generally increase from lower to higher BE/ME quintiles. 
Table A1: One-factor model: Regression of excess stock returns on RMRF, SMB, HML, and HVaRL

\begin{tabular}{|c|c|c|c|c|c|c|c|c|c|c|}
\hline \multirow{2}{*}{ Size quintile } & \multirow{2}{*}{ Low } & \multicolumn{9}{|c|}{$\mathrm{BE} / \mathrm{ME}$ quintile } \\
\hline & & 2 & 3 & 4 & High & Low & 2 & 3 & 4 & High \\
\hline & \multicolumn{5}{|c|}{ RM-RF slope (average $=0.547)$} & \multicolumn{5}{|c|}{ t-statistics } \\
\hline Small & $0.361^{*}$ & $0.498^{*}$ & $0.436^{*}$ & $0.420^{*}$ & $0.329^{*}$ & 4.31 & 6.69 & 5.21 & 6.02 & 3.07 \\
\hline 2 & $0.246^{*}$ & $0.480^{*}$ & $0.230^{*}$ & $0.455^{*}$ & $0.655^{*}$ & 4.00 & 8.34 & 4.66 & 8.83 & 7.82 \\
\hline 3 & $0.465^{*}$ & $0.406^{*}$ & $0.416^{*}$ & $0.616^{*}$ & $0.781^{*}$ & 8.65 & 7.28 & 7.72 & 12.04 & 13.06 \\
\hline 4 & $0.402^{*}$ & $0.436^{*}$ & $0.416^{*}$ & $0.555^{*}$ & $1.168^{*}$ & 7.82 & 9.33 & 9.68 & 11.57 & 18.78 \\
\hline \multirow[t]{2}{*}{ Big } & $0.600^{*}$ & $0.714^{*}$ & $0.844^{*}$ & $0.647^{*}$ & $1.120^{*}$ & 8.99 & 18.40 & 26.81 & 14.93 & 35.69 \\
\hline & \multicolumn{5}{|c|}{ Adjusted $R^{2}$ (average $=0.359$ ) } & \multicolumn{5}{|c|}{ SSE } \\
\hline Small & 0.099 & 0.214 & 0.140 & 0.180 & 0.050 & 0.10 & 0.09 & 0.10 & 0.09 & 0.13 \\
\hline 2 & 0.085 & 0.299 & 0.114 & 0.323 & 0.272 & 0.08 & 0.07 & 0.06 & 0.06 & 0.10 \\
\hline 3 & 0.314 & 0.244 & 0.267 & 0.472 & 0.513 & 0.07 & 0.07 & 0.07 & 0.06 & 0.07 \\
\hline 4 & 0.272 & 0.348 & 0.365 & 0.452 & 0.686 & 0.06 & 0.06 & 0.05 & 0.06 & 0.08 \\
\hline \multirow[t]{2}{*}{ Big } & 0.331 & 0.677 & 0.817 & 0.580 & 0.888 & 0.08 & 0.05 & 0.04 & 0.05 & 0.04 \\
\hline & \multicolumn{5}{|c|}{ HVaRL slope (average $=1.002)$} & \multicolumn{5}{|c|}{ t-statistics } \\
\hline Small & $1.255^{*}$ & $1.272^{*}$ & $0.551^{*}$ & $1.002^{*}$ & $1.493^{*}$ & 9.54 & 10.58 & 3.38 & 8.36 & 8.86 \\
\hline 2 & $0.615^{*}$ & $0.852^{*}$ & $0.541^{*}$ & $0.865^{*}$ & $1.731^{*}$ & 5.59 & 7.80 & 6.13 & 9.10 & 14.14 \\
\hline 3 & $0.741^{*}$ & $0.581^{*}$ & $0.760^{*}$ & $1.152^{*}$ & $1.471^{*}$ & 6.97 & 5.25 & 7.55 & 12.14 & 13.35 \\
\hline 4 & $0.803^{*}$ & $0.861^{*}$ & & & & 8.63 & & 7.31 & 10.91 & 14.01 \\
\hline \multirow[t]{2}{*}{ Big } & $0.587^{*}$ & $0.987^{*}$ & $1.029^{*}$ & $0.889^{*}$ & $1.443^{*}$ & 4.04 & 9.76 & 9.28 & 8.59 & 10.88 \\
\hline & \multicolumn{5}{|c|}{ Adjusted $R^{2}$ (average $=0.322$ ) } & \multicolumn{5}{|c|}{ SSE } \\
\hline Small & 0.360 & 0.410 & 0.061 & 0.301 & 0.326 & 0.09 & 0.08 & 0.11 & 0.08 & 0.11 \\
\hline 2 & 0.159 & 0.272 & 0.186 & 0.338 & 0.554 & 0.07 & 0.07 & 0.06 & 0.06 & 0.08 \\
\hline 3 & 0.229 & 0.143 & 0.259 & 0.478 & 0.526 & 0.07 & 0.07 & 0.07 & 0.06 & 0.07 \\
\hline 4 & 0.315 & 0.394 & 0.247 & 0.424 & 0.550 & 0.06 & 0.06 & 0.06 & 0.06 & 0.09 \\
\hline \multirow[t]{2}{*}{ Big } & 0.088 & 0.371 & 0.347 & 0.313 & 0.423 & 0.10 & 0.07 & 0.07 & 0.07 & 0.09 \\
\hline & \multicolumn{5}{|c|}{ SMB slope (average $=-0.280$ ) } & \multicolumn{5}{|c|}{ t-statistics } \\
\hline Small & $0.653^{*}$ & 0.213 & -0.082 & 0.218 & $1.087^{*}$ & 3.67 & 1.21 & -0.44 & 1.36 & 5.05 \\
\hline 2 & $0.268^{* *}$ & -0.126 & $0.226^{* *}$ & 0.012 & -0.008 & 2.01 & -0.87 & 2.08 & 0.10 & -0.04 \\
\hline 3 & $-0.432^{*}$ & -0.201 & -0.139 & $-0.315^{* *}$ & $-0.649^{*}$ & -3.27 & -1.51 & -1.05 & -2.16 & -3.75 \\
\hline 4 & -0.152 & $-0.304^{* *}$ & $-0.385^{*}$ & $-0.379^{*}$ & $-1.416^{*}$ & -1.21 & -2.55 & -3.52 & -2.85 & -6.92 \\
\hline \multirow[t]{2}{*}{ Big } & $-1.107^{*}$ & $-0.834^{*}$ & $-1.054^{*}$ & $-0.700^{*}$ & $-1.420^{*}$ & -7.50 & -6.54 & -8.08 & -5.41 & -8.78 \\
\hline & \multicolumn{5}{|c|}{ Adjusted $\mathrm{R}^{2}$ (average $=0.078$ ) } & \multicolumn{5}{|c|}{ SSE } \\
\hline Small & 0.072 & 0.003 & -0.005 & 0.005 & 0.132 & 0.10 & 0.10 & 0.11 & 0.09 & 0.13 \\
\hline 2 & 0.018 & -0.001 & 0.020 & -0.006 & -0.006 & 0.08 & 0.08 & 0.06 & 0.08 & 0.12 \\
\hline 3 & 0.057 & 0.008 & 0.001 & 0.022 & 0.075 & 0.08 & 0.08 & 0.08 & 0.09 & 0.10 \\
\hline 4 & 0.003 & 0.033 & 0.066 & 0.042 & 0.225 & 0.07 & 0.07 & 0.06 & 0.08 & 0.12 \\
\hline
\end{tabular}




\begin{tabular}{l|ccccc|ccccc}
\hline Size quintile & Low & $\mathbf{2}$ & $\mathbf{3}$ & $\mathbf{4}$ & High & Low & $\mathbf{2}$ & $\mathbf{3}$ & $\mathbf{4}$ & High \\
\hline Big & 0.255 & 0.206 & 0.286 & 0.149 & 0.321 & 0.09 & 0.08 & 0.08 & 0.08 & 0.10 \\
\hline \multirow{5}{*}{ Small } & 0.037 & $0.683^{*}$ & $0.948^{*}$ & $0.996^{*}$ & $1.510^{*}$ & 0.21 & 4.20 & 5.63 & 7.34 & 7.94 \\
2 & 0.106 & $0.394^{*}$ & $0.485^{*}$ & $0.645^{*}$ & $1.469^{*}$ & 0.81 & 2.88 & 4.86 & 5.50 & 9.00 \\
3 & $0.404^{*}$ & $0.389^{*}$ & $0.455^{*}$ & $0.846^{*}$ & $1.283^{*}$ & 3.15 & 3.06 & 3.70 & 6.66 & 9.01 \\
4 & $0.464^{*}$ & $0.750^{*}$ & $0.547^{*}$ & $0.852^{*}$ & $1.589^{*}$ & 3.96 & 7.35 & 5.40 & 7.48 & 8.44 \\
Big & -0.013 & $0.506^{*}$ & $0.724^{*}$ & $0.554^{*}$ & $1.190^{*}$ & -0.08 & 3.79 & 5.22 & 4.29 & 7.16 \\
\hline \multirow{5}{*}{ Small } & -0.006 & 0.094 & 0.160 & 0.247 & 0.278 & 0.11 & 0.10 & 0.10 & 0.08 & 0.12 \\
2 & -0.002 & 0.043 & 0.123 & 0.154 & 0.332 & 0.08 & 0.08 & 0.06 & 0.07 & 0.10 \\
3 & 0.052 & 0.049 & 0.073 & 0.212 & 0.332 & 0.08 & 0.08 & 0.07 & 0.08 & 0.09 \\
4 & 0.084 & 0.248 & 0.149 & 0.255 & 0.304 & 0.07 & 0.06 & 0.06 & 0.07 & 0.11 \\
Big & -0.006 & 0.077 & 0.140 & 0.098 & 0.238 & 0.10 & 0.08 & 0.08 & 0.08 & 0.10 \\
\hline
\end{tabular}

Note: ${ }^{* * *}$, and ${ }^{* *}=$ significant at 1,5 , and 10 percent, respectively. The table reports statistics for the period January 1995 to June 2008.

Source: Authors' calculations.

\section{Two-factor model}

In order to determine the relative efficacy of the VaR factor, we consider a set of two-factor models in which the monthly returns on the 25 portfolios are regressed on RM-RF along with SMB, HML, or HVaRL. The results are given in Table A2. Interestingly, the RM-RF and HVaRL two-factor model captures a greater degree of time variation in portfolio returns than the other two-factor models.

Panel A of the table gives the results of the excess stock returns regressed on RM-RF and HVaRL. When used alone, RM-RF has a low degree of explanatory power in terms of the adjusted R-squared value. However, when HVaRL is added to the regression, both variables capture a larger time series variation. RM-RF, when used alone, yields an average adjusted R-squared value of 0.359 (Table A1). In the two-factor regressions (Table A2, panel A), the average adjusted R-squared value is 0.452 . The t-statistics for the RM-RF slopes are generally greater than 2 .

As expected, 22 of the $25 \mathrm{HVaRL}$ coefficients are statistically significant at the 1 percent level. The t-statistic ranges from -0.7 to 10.0 . Panel B of Table A2 gives the regression results for the portfolios with $\mathrm{RM}-\mathrm{RF}$ and SMB. The betas for stocks are all between 0 and 2. Six of the SMB slope coefficients are insignificant and the average adjusted Rsquared value is 0.454 . 
Table A2: Two-factor model: Regression of excess stock returns on RMRF and HVaRL or SMB or HML

$\mathrm{BE} / \mathrm{ME}$ quintile

Panel A: RM-RF and HVaRL

\begin{tabular}{|c|c|c|c|c|c|c|c|c|c|c|}
\hline Size quintile & Low & 2 & 3 & 4 & High & Low & 2 & 3 & 4 & High \\
\hline & \multicolumn{5}{|c|}{ RM-RF slope (average $=0.352)$} & \multicolumn{5}{|c|}{ t-statistics } \\
\hline Small & -0.056 & $0.147^{* * *}$ & $0.400^{*}$ & $0.158^{* *}$ & $-0.220^{* *}$ & -0.64 & 1.85 & 3.86 & 2.00 & -1.99 \\
\hline 2 & 0.078 & $0.324^{*}$ & 0.089 & $0.278^{*}$ & $0.164^{* *}$ & 1.07 & 4.74 & 1.54 & 4.68 & 2.04 \\
\hline 3 & $0.353^{*}$ & $0.340^{*}$ & $0.267^{*}$ & $0.384^{*}$ & $0.483^{*}$ & 5.43 & 4.96 & 4.18 & 6.94 & 7.73 \\
\hline 4 & $0.225^{*}$ & $0.249^{*}$ & $0.327^{*}$ & $0.365^{*}$ & $0.844^{*}$ & 3.81 & 4.77 & 6.29 & 6.78 & 13.23 \\
\hline \multirow[t]{2}{*}{ Big } & $0.635^{*}$ & $0.616^{*}$ & $0.795^{*}$ & $0.561^{*}$ & $1.015^{*}$ & 7.68 & 13.29 & 20.63 & 10.67 & 27.94 \\
\hline & \multicolumn{5}{|c|}{ HVaRL slope $($ average $=0.614)$} & & & & & \\
\hline Small & $1.315^{*}$ & $1.107^{*}$ & 0.113 & $0.826^{*}$ & $1.735^{*}$ & 8.09 & 7.48 & 0.58 & 5.62 & 8.42 \\
\hline 2 & $0.529^{*}$ & $0.493^{*}$ & $0.443^{*}$ & $0.558^{*}$ & $1.550^{*}$ & 3.90 & 3.88 & 4.08 & 5.05 & 10.37 \\
\hline 3 & $0.353^{*}$ & 0.205 & $0.469^{*}$ & $0.731^{*}$ & $0.941^{*}$ & 2.92 & 1.61 & 3.95 & 7.10 & 8.09 \\
\hline 4 & $0.555^{*}$ & $0.588^{*}$ & $0.280^{*}$ & $0.601^{*}$ & $1.019^{*}$ & 5.04 & 6.04 & 2.90 & 6.00 & 8.59 \\
\hline \multirow[t]{2}{*}{ Big } & -0.111 & $0.310^{*}$ & $0.155^{* *}$ & $0.272^{*}$ & $0.330^{*}$ & -0.72 & 3.60 & 2.16 & 2.79 & 4.89 \\
\hline & \multicolumn{5}{|c|}{ Adjusted $R^{2}$ (average $=0.452$ ) } & \multicolumn{5}{|c|}{ SSE } \\
\hline Small & 0.357 & 0.415 & 0.136 & 0.311 & 0.339 & 0.09 & 0.08 & 0.10 & 0.08 & 0.11 \\
\hline 2 & 0.160 & 0.355 & 0.193 & 0.413 & 0.563 & 0.07 & 0.07 & 0.06 & 0.06 & 0.08 \\
\hline 3 & 0.345 & 0.252 & 0.328 & 0.597 & 0.653 & 0.06 & 0.07 & 0.06 & 0.06 & 0.06 \\
\hline 4 & 0.368 & 0.466 & 0.393 & 0.550 & 0.784 & 0.06 & 0.05 & 0.05 & 0.05 & 0.06 \\
\hline Big & 0.329 & 0.700 & 0.821 & 0.597 & 0.902 & 0.08 & 0.05 & 0.04 & 0.05 & 0.04 \\
\hline
\end{tabular}

Panel B: RM-RF and SMB

\begin{tabular}{|c|c|c|c|c|c|c|c|c|c|c|}
\hline Size quintile & Low & 2 & 3 & 4 & High & Low & 2 & 3 & 4 & High \\
\hline & \multicolumn{5}{|c|}{ RM-RF slope (average $=0.714$ ) } & \multicolumn{5}{|c|}{ t-statistics } \\
\hline Small & $0.827^{*}$ & $0.850^{*}$ & $0.629^{*}$ & $0.732^{*}$ & $0.964^{*}$ & 10.08 & 10.75 & 6.27 & 9.73 & 9.52 \\
\hline 2 & $0.489^{*}$ & $0.678^{*}$ & $0.446^{*}$ & $0.698^{*}$ & $0.995^{*}$ & 7.12 & 10.26 & 8.32 & 12.78 & 10.69 \\
\hline 3 & $0.524^{*}$ & $0.532 *$ & $0.574^{*}$ & $0.804^{*}$ & $0.914^{*}$ & 7.93 & 7.96 & 9.09 & 13.86 & 12.72 \\
\hline 4 & $0.547^{*}$ & $0.534^{*}$ & $0.470^{*}$ & $0.684^{*}$ & $1.175^{*}$ & 9.04 & 9.49 & 8.92 & 12.05 & 15.27 \\
\hline \multirow[t]{2}{*}{ Big } & $0.442^{*}$ & $0.732^{*}$ & $0.837^{*}$ & $0.688^{*}$ & $1.100^{*}$ & 5.55 & 15.27 & 21.48 & 12.89 & 28.40 \\
\hline & \multicolumn{5}{|c|}{ SMB slope (average $=0.596)$} & & & & & \\
\hline Small & $1.670^{*}$ & $1.257^{*}$ & $0.690^{*}$ & $1.118^{*}$ & $2.272^{*}$ & 9.70 & 7.59 & 3.28 & 7.09 & 10.69 \\
\hline 2 & $0.869^{*}$ & $0.706^{*}$ & $0.774^{*}$ & $0.871^{*}$ & $1.214^{*}$ & 6.03 & 5.10 & 6.88 & 7.60 & 6.22 \\
\hline 3 & 0.211 & $0.452 *$ & $0.566^{*}$ & $0.672^{*}$ & $0.473^{*}$ & 1.53 & 3.22 & 4.27 & 5.52 & 3.14 \\
\hline 4 & $0.519^{*}$ & $0.352 *$ & $0.192^{* * *}$ & $0.461^{*}$ & 0.027 & 4.10 & 2.98 & 1.74 & 3.87 & 0.17 \\
\hline \multirow[t]{2}{*}{ Big } & $-0.563^{*}$ & 0.065 & -0.026 & 0.145 & -0.068 & -3.37 & 0.65 & -0.32 & 1.30 & -0.85 \\
\hline & \multicolumn{5}{|c|}{ Adjusted $R^{2}$ (average $\left.=0.454\right)$} & \multicolumn{5}{|c|}{ SSE } \\
\hline Small & 0.430 & 0.419 & 0.189 & 0.373 & 0.444 & 0.08 & 0.08 & 0.10 & 0.08 & 0.10 \\
\hline 2 & 0.251 & 0.393 & 0.313 & 0.501 & 0.411 & 0.07 & 0.07 & 0.05 & 0.05 & 0.09 \\
\hline 3 & 0.320 & 0.286 & 0.338 & 0.554 & 0.539 & 0.07 & 0.07 & 0.06 & 0.06 & 0.07 \\
\hline
\end{tabular}




\begin{tabular}{l|ccccc|ccccc}
\hline Size quintile & Low & $\mathbf{2}$ & $\mathbf{3}$ & $\mathbf{4}$ & High & Low & $\mathbf{2}$ & $\mathbf{3}$ & $\mathbf{4}$ & High \\
\hline 4 & 0.337 & 0.379 & 0.373 & 0.496 & 0.684 & 0.06 & 0.06 & 0.05 & 0.06 & 0.08 \\
Big & 0.372 & 0.676 & 0.816 & 0.581 & 0.888 & 0.08 & 0.05 & 0.04 & 0.05 & 0.04 \\
\hline
\end{tabular}

Panel C: RM-RF and HML

\begin{tabular}{|c|c|c|c|c|c|c|c|c|c|c|}
\hline Size quintile & Low & 2 & 3 & 4 & High & Low & 2 & 3 & 4 & High \\
\hline & \multicolumn{5}{|c|}{ RM-RF slope (average $=0.484)$} & \multicolumn{5}{|c|}{ t-statistics } \\
\hline Small & $0.418^{*}$ & $0.433^{*}$ & $0.299^{*}$ & $0.268^{*}$ & 0.044 & 4.62 & 5.40 & 3.44 & 3.86 & 0.44 \\
\hline 2 & $0.267^{*}$ & $0.478^{*}$ & $0.161^{*}$ & $0.391^{*}$ & $0.439^{*}$ & 3.99 & 7.61 & 3.09 & 7.14 & 5.47 \\
\hline 3 & $0.457^{*}$ & $0.391^{*}$ & $0.388^{*}$ & $0.535^{*}$ & $0.631^{*}$ & 7.80 & 6.44 & 6.63 & 10.03 & 10.92 \\
\hline 4 & $0.369^{*}$ & $0.344^{*}$ & $0.367^{*}$ & $0.462^{*}$ & $1.018^{*}$ & 6.63 & 7.24 & 8.01 & 9.46 & 16.76 \\
\hline \multirow[t]{2}{*}{ Big } & $0.713^{*}$ & $0.729^{*}$ & $0.833^{*}$ & $0.639 *$ & $1.052^{*}$ & 10.31 & 17.26 & 24.30 & 13.52 & 33.50 \\
\hline & \multicolumn{5}{|c|}{ HML slope (average $=0.324$ ) } & & & & & \\
\hline Small & -0.297 & $0.3365^{* *}$ & $0.7084^{*}$ & $0.781^{*}$ & $1.474^{*}$ & -1.61 & 2.06 & 4.00 & 5.51 & 7.11 \\
\hline 2 & -0.107 & 0.011 & $0.357^{*}$ & $0.332^{* *}$ & $1.117^{*}$ & -0.79 & 0.09 & 3.37 & 2.99 & 6.84 \\
\hline 3 & 0.038 & 0.076 & 0.145 & $0.418^{*}$ & $0.779^{*}$ & 0.33 & 0.62 & 1.22 & 3.86 & 6.63 \\
\hline 4 & 0.169 & $0.475^{*}$ & $0.253^{*}$ & $0.482^{*}$ & $0.775^{*}$ & 1.49 & 4.92 & 2.72 & 4.85 & 6.28 \\
\hline \multirow[t]{2}{*}{ Big } & $-0.584^{*}$ & -0.077 & 0.058 & 0.043 & $0.349^{*}$ & -4.15 & -0.90 & 0.84 & 0.45 & 5.47 \\
\hline & \multicolumn{5}{|c|}{ Adjusted $R^{2}$ (average $\left.=0.405\right)$} & \multicolumn{5}{|c|}{ SSE } \\
\hline Small & 0.108 & 0.229 & 0.213 & 0.307 & 0.275 & 0.10 & 0.09 & 0.10 & 0.08 & 0.12 \\
\hline 2 & 0.083 & 0.294 & 0.168 & 0.355 & 0.434 & 0.08 & 0.07 & 0.06 & 0.06 & 0.09 \\
\hline 3 & 0.310 & 0.241 & 0.269 & 0.514 & 0.616 & 0.07 & 0.07 & 0.07 & 0.06 & 0.07 \\
\hline 4 & 0.278 & 0.431 & 0.390 & 0.520 & 0.747 & 0.06 & 0.05 & 0.05 & 0.06 & 0.07 \\
\hline Big & 0.393 & 0.677 & 0.816 & 0.577 & 0.905 & 0.08 & 0.05 & 0.04 & 0.05 & 0.04 \\
\hline
\end{tabular}

Note: ${ }^{*}{ }^{* *}$, and ${ }^{* * *}=$ significant at 1,5 , and 10 percent, respectively. The table reports statistics for the period January 1995 to June 2008.

Source: Authors' calculations.

HML, when used together with RM-RF, captures a smaller degree of time series variation in stock returns compared to SMB. As panel C shows, ten of the HML coefficients are statistically insignificant and the average adjusted R-squared value is 0.405 . As in Table A1, the slopes of SMB and HML are related to, respectively, size and BE/ME. In every $\mathrm{BE} / \mathrm{ME}$ quintile, the SMB slopes generally decrease from smaller to larger size quintiles. In every size quintile of stocks, the HML slopes generally increase from negative values for the lowest $\mathrm{BE} / \mathrm{ME}$ quintile to positive values for the highest $\mathrm{BE} / \mathrm{ME}$ quintile. 